\title{
Neuropilin-1 is involved in regulation of apoptosis and migration of human colon cancer
}

\author{
TAKEHIKO OCHIUMI ${ }^{1}$, YASUHIKO KITADAI ${ }^{1}$, SHINJI TANAKA $^{2}$, MORIHISA AKAGI $^{3}$, \\ MASAHARU YOSHIHARA ${ }^{4}$ and KAZUAKI CHAYAMA ${ }^{1}$ \\ ${ }^{1}$ Department of Medicine and Molecular Science, Graduated School of Biomedical Sciences, Hiroshima University; \\ ${ }^{2}$ Department of Endoscopy, Hiroshima University Hospital; ${ }^{3}$ Department of Internal Medicine, Hiroshima \\ Prefectural Hospital; ${ }^{4}$ Department of Health Service Center, Hiroshima University, Higashi, Hiroshima, Japan
}

Received January 23, 2006; Accepted March 20, 2006

\begin{abstract}
Vascular endothelial growth factor (VEGF) plays critical roles in cancer aggressiveness. We investigated the clinical and biological significance of neuropilin (NP)-1, a member of the VEGF receptor family, in colon carcinoma. We transfected NP-1-specific small interfering RNA (siRNA) into a human colon adenocarcinoma cell line, WiDR, and investigated its effect on proliferation, migration, and apoptosis. We also examined the relationship between clinicopathologic features and NP-1 expression in 146 patients with advanced colorectal carcinoma who had undergone surgery. Inhibition of NP-1 expression in WiDR cells by RNA interference decreased cell migration (no treatment, 143.3/field; mock, 146.8/field; scrambled siRNA, 134.6/field; NP-1 siRNA 79.6/field) and promoted apoptosis (no treatment, 3.52\%; scrambled siRNA, 3.80\%; NP-1 siRNA, 14.22\%), but did not alter cell proliferation. In patients with advanced colorectal carcinoma, those with tumors with high levels of NP-1 staining showed a significantly higher incidence of lymph node $(73.0 \%)$ or liver $(86.2 \%)$ metastasis, greater microvessel density (MVD) (60.4/field), greater number of proliferating carcinoma cells $(48.6 \%)$, and lesser number of apoptotic carcinoma cells $(5.70 \%$ ) than those with tumors with low levels of NP-1 staining (lymph node, 56.9\%; liver, 59.8\%; MVD, 47.8/field; proliferating cells, 42.0\%; apoptosis, 8.44\%o). Survival for patients with tumors with high levels of NP-1 staining was significantly shorter than for those with tumors with low levels of NP-1 staining. Our results suggest that autocrine-NP-1 pathways control the migration and survival
\end{abstract}

Correspondence to: Dr Yasuhiko Kitadai, Department of Medicine and Molecular Science, Hiroshima University, 1-2-3 Kasumi, Minami-ku, Hiroshima 734-8551, Japan

E-mail: kitadai@hiroshima-u.ac.jp

Key words: neuropilin-1, apoptosis, migration, prognosis, colon carcinoma of colon carcinoma cells. NP-1 expression may stimulate tumor growth by enhanced angiogenesis and suppression of tumor cell apoptosis, which lead to metastasis and poor prognosis.

\section{Introduction}

Neuropilin (NP) was first identified as a novel membrane protein from the optic tract of Xenopus laevis (1). NP-1 functions as a semaphorin (SEMA) receptor in the developing nervous system (2-4). NP-1 also plays roles in vasculogenesis and angiogenesis; transgenic overexpression or knockout of the NP-1 gene results in lethal abnormalities of the cardiovascular system $(5,6)$. Although NP-1 contains a relatively large extracellular domain of 860 amino acids, NP-1 contains a very short transmembrane domain of 23 amino acids and an intracellular domain of 40 amino acids, not including the tyrosine-kinase domain (2-4). Consequently, focused on the extracellular domain that contained five domains [a1/a2, b1/b2, and c (a MAM domain) (2-4)], NP-1 appears to function as a coreceptor for vascular endothelial growth factor (VEGF) receptor 2 (VEGFR-2) for the binding of VEGF165 (7) and plexin-A1 and -A2 for the binding of SEMA $(8,9)$. Coexpression of NP-1 and VEGFR-2 on endothelial cells (ECs) enhanced VEGFR-2-mediated migration induced by VEGF165 (7). The ability of NP-1 to deliver SEMA3A-associated chemorepulsive signals is dependent on NP-1 associations with plexins, proteins with homology to Met $(8,9)$. However, recent studies have shown that the three C-terminal amino acids of the intracellular domain of NP-1 are responsible for interaction with the PSD-95-Dlg/ZO (PDZ) domain-containing C-terminal two-thirds of NP-1-interacting protein $(10,11)$ and that NP-1 alone can mediate VEGFinduced EC migration via a PDZ domain-containing protein by a chimeric receptor technique (12).

Many recent studies have shown that NP-1 is expressed not only in ECs but also in cells of several tumors, including neuroblastomas; astrocytomas; and breast, prostate, lung, pancreas, bile duct, gastric, and colon cancers. Several reports have focused on the role of NP-1 in tumor progression and malignant potential (7,13-28). Coexpression of NP-1 and -2 has been shown to correlate significantly with a poor prognosis in patients with non-small cell lung cancer (17). In addition, 
VEGF165 has been suggested to be an autocrine survival factor for NP-expressing breast cancer cells lacking VEGFR-2 $(21,22)$. It has been reported that NP-1 is expressed at high levels in colon cancer (20) and that NP-1 contributes to tumor development and angiogenesis of colon cancer in nude mice (25). Several tumors, lacking VEGFR-1 and/or VEGFR-2, have been reported to express NP-1 (7,21-24). On the basis of these results, we hypothesized that there was an autocrine VEGF pathway mediated by NP-1 in colon carcinoma. To determine the role of autocrine VEGF165/NP-1 pathway, we examined the effect of inhibition of NP-1 expression in vitro using an RNA interference (RNAi) technique. In particular, we focused on the effect of NP-1 inhibition on proliferation, invasion, and apoptosis in tumor metastasis. We also investigated the relationship between NP-1 expression and clinicopathologic features, angiogenesis, cancer cell apoptosis, or cancer cell proliferation in patients with advanced colorectal carcinoma.

\section{Materials and methods}

Cell cultures. Four cell lines established from human colon adenocarcinoma (COLO320DM, COLO201, DLD-1, and WiDR) were obtained from the JCRB Cell Bank (Osaka, Japan). Cells were routinely maintained in RPMI-1640 medium (Nissui Pharmaceutical Co. Ltd., Tokyo, Japan) supplemented with $10 \%$ heat-inactivated fetal bovine serum (FBS) (Cansera International Inc., Ontario, Canada) at $37^{\circ} \mathrm{C}$ in a humidified atmosphere of $95 \%$ air and $5 \% \mathrm{CO}_{2}$. Human adult microvessel endothelial cells (HMVECs) were purchased from Cambrex Corp. (Walkersville, MD) and cultured in endothelial basal medium-2 supplemented with hydrocortisone, VEGF, ascorbic acid, gentamicin, amphotericin B, basic fibroblast growth factor, insulin-like growth factor-1, heparin, epidermal growth factor, and 5\% FBS (Cambrex Corp.).

Clinical samples. One hundred forty-six patients who underwent surgical resection for advanced colorectal carcinoma without preoperative treatment at Hiroshima University Hospital between 1983 and 1997 were enrolled in this study. Patients comprised 91 men and 55 women; mean age was $63.4 \pm 10.8$ years. These patients were followed-up for a mean of $61.2 \pm 28.6$ months after surgical resection. Patients who died of other causes were excluded from this study. All patients with liver metastasis were treated with adjuvant chemotherapy after surgical resection. Histological classification was assessed on hematoxylin- and -eosin-stained sections according to the WHO classification system (29). Invasion was classified by depth into four groups according to the General Rules for the Study of Colorectal Cancer in Japan (30): mp (invasion of the muscularis propria), ss (a1) (invasion of the subserosa or subadventitia), se (a2) (invasion of the serosa or adventitia), and si (ai) (invasion of adjacent structures).

Small interfering RNA (siRNA) transfection. siRNA targeting NP-1 (sense: 5'-CUU CAA CCC UCA CUU CGA UTT-3') and scrambled siRNA targeting NP-1 (sense: 5'-ACA CCU GUC CUA UCC AUC UTT-3') (scramble) were designed and synthesized by Takara Bio Inc. (Tokyo, Japan). WiDR cells were plated at an approximate cell density of $6.25 \times 10^{4}$ cells in $1.9-\mathrm{cm}^{2}$ dishes in RPMI-1640 medium containing 10\% FBS (complete medium) such that they would reach $60 \%$ confluence by the following day. Transfections of the siRNA targeting NP-1 (siRNA final concentration: 1, 5, or $25 \mathrm{nM}$ ) were performed in RPMI-1640 medium with TransIT-TKO Transfection Reagent (Mirus Bio Corp., MD, USA) in accordance with the manufacturer's recommended procedure. siRNAs were removed $48 \mathrm{~h}$ after transfection, the cells were cultured in complete medium, and used for experiments. The complete medium was changed after $48 \mathrm{~h}$. WiDR cells treated with TransIT-TKO alone (mock) were used as a negative control.

Semi-quantitative RT-PCR and quantitative RT-PCR. Total RNA was extracted from human colon carcinoma cell lines, WiDR cells transfected with siRNA, and HMVECs with RNeasy Kit (Qiagen, Hilden, Germany) according to the manufacturer's instructions. cDNA was synthesized from $1 \mu \mathrm{g}$ total RNA with a first strand cDNA synthesis kit (Amersham Biosciences UK Ltd., Buckinghamshire, UK). After reverse transcription of RNA into cDNA, quantitative RT-PCR was performed with a LightCycler-FastStart DNA Master SYBR-Green I kit (Roche, Mannheim, Germany) and semiquantitative RT-PCR was performed with an AmpliTaq Gold kit (Roche, Branchburg, NJ) according to the manufacturer's recommendations. Quantitative RT-PCR was used to monitor gene expression and was performed with a LightCycler system and LightCycler data analysis software ver. 3.5 (Roche) in accordance with standard procedures. Primers for PCR were synthesized based on the reported sequences of NP-1, NP-2, VEGFR-1, VEGFR-2, VEGF, SEMA3A, plexin-A1 and GAPDH $(16,23,30)$ and are listed in Table I. Quantitative RT-PCR was performed for 40 cycles under the following conditions: denaturation for $15 \mathrm{sec}$ at $95^{\circ} \mathrm{C}$, extension for $12 \mathrm{sec}$ at $72^{\circ} \mathrm{C}$, and annealing for $5 \mathrm{sec}$ at $60^{\circ} \mathrm{C}$ for NP-1 and for $5 \mathrm{sec}$ at $55^{\circ} \mathrm{C}$ for GAPDH. Semi-quantitative RT-PCR was performed under the following conditions: denaturation for $1 \mathrm{~min}$ at $94^{\circ} \mathrm{C}$ and extension for $1 \mathrm{~min}$ at $72^{\circ} \mathrm{C}$. Each semi-quantitative RT-PCR cycle condition and annealing temperature for amplification of these cDNAs was performed under the conditions listed in Table I. After the reaction, semi-quantitative RT-PCR products were resolved on 5\% nondenaturing polyacrylamide gels in Tris-borate-EDTA buffer. RT-PCR reactions in the absence of reverse transcriptase showed no specific bands (data not shown).

Western blot analysis. Cells were homogenized in lysis buffer containing $8 \mathrm{M}$ urea, $10 \%$ SDS, $1 \mathrm{M}$ DTT, and protease inhibitors on ice. Protein extracts $(30 \mu \mathrm{g})$ were dissolved in sample buffer with 2-mercaptoethanol, boiled, separated by SDS-PAGE, and transferred to Immobilon membranes (Millipore, Bedford, MA) according to the manufacturer's instructions. The membranes were then blocked with $5 \%$ powdered skim milk dissolved in Tris-buffered saline containing $0.1 \%$ Tween-20, and mouse monoclonal antiNP-1 antibody A-12 (1:100; Santa Cruz Biotechnology Inc., Santa Cruz, CA) or rabbit polyclonal anti-phosphoeukaryotic initiation factor 2 (eIF2 $\alpha)$ \#9721 (1:1000; Cell Signaling Technology, Beverly, MA) were used in primary 
Table I. The primer sequences, cycle conditions, annealing temperature, and PCR products of genes.

\begin{tabular}{|c|c|c|c|c|c|}
\hline Gene & Upper primer $\left(5^{\prime}-3^{\prime}\right)$ & Lower primer $\left(5^{\prime}-3^{\prime}\right)$ & $\begin{array}{l}\text { Number } \\
\text { of cycles }\end{array}$ & $\begin{array}{l}\text { Annealing } \\
\text { temperature }\end{array}$ & $\begin{array}{r}\text { Product length } \\
(\mathrm{bp})\end{array}$ \\
\hline & & & & & VEGF189 264 \\
\hline \multirow[t]{2}{*}{ VEGF } & CAC ATA GGA GAG ATG AGC & CCG CCT CGG CTT GTC ACA & 28 & 57 & VEGF165 210 \\
\hline & & & & & VEGF121 74 \\
\hline SEMA 3A & GACTTTGCTATCTTCCGAACTCTTGGGCAC & GCTATACATACACACGGCTGATCCCTTG & 32 & 62 & 440 \\
\hline VEGFR1 & GTCACAGAAGAGGATGAAGGTGTC & CACAGTCCGGCACGTAGGTGATT & 35 & 62 & 413 \\
\hline VEGFR2 & GCATCTCATCTGTTACAGC & CTTCATCAATCTTTACCCC & 35 & 62 & 331 \\
\hline NP-1 & AAAAGCCCACGGTCATAG & TGTCATCCACAGCAATCC & 32 & 60 & 503 \\
\hline NP-2 & CAAGTTGCTGTGGGTCATAG & AATTGCTCCAGTCCACCTC & 30 & 60 & 283 \\
\hline plexin-Al & ACTACCGGACATATGCCATGC & CTCCTTGGCCTGGGTGACCG & 35 & 60 & 631 \\
\hline GAPDH & ATC ATC CCT GCC TCT ACT GG & CCC TCC GAC GCC TGC TTC AC & 25 & 52 & 188 \\
\hline
\end{tabular}

reaction. Peroxidase-conjugated anti-mouse or anti-rabbit goat IgG (1:1000; MBL, Nagoya, Japan) was used as secondary antibody. Antibody-protein complexes were detected with ECL Western blotting detection reagents (Amersham Pharmacia Biotech UK Ltd.) and were developed with a ChemiDoc XRS-J system and Quantity One software ver. 4.5 (Bio-Rad Laboratories, Inc., Hercules, CA).

Migration assay. The migration potential of NP-1-inhibited WiDR cells was determined by a modified two-chamber invasion assay. Twelve-well transwell plates with a $12-\mu \mathrm{m}$ pore size in the upper compartment of a Boyden chamber (Corning Life Science Inc., Acton, MA) were coated with $100 \mu \mathrm{g} / \mathrm{ml}$ Matrigel (Becton Dickinson Labware, Lincoln Park, NJ). After siRNAs were removed, WiDR cells were washed twice with PBS, treated with trypsin, and incubated $\left(2.5 \times 10^{5}\right.$ cells per 6 -well plate in complete medium) in a humidified atmosphere of $95 \%$ air and $5 \% \mathrm{CO}_{2}$ at $37^{\circ} \mathrm{C}$ for $24 \mathrm{~h}$ such that they would reach $60 \%$ confluence the following day. After adherent cells were released by trypsinization for 5 min, $1 \times 10^{5}$ cells of each treatment group were suspended in RPMI-1640 medium containing 1\% FBS (1\%-FBS medium) in the upper compartment of a Boyden chamber and VEGF165 (final concentration $20 \mathrm{ng} / \mathrm{ml}$ ) (Strathmann Biotec AG, Hamburg, Germany) was added as a chemoattractant to $1 \%$-FBS medium in the lower compartment of the chamber. After 36-h incubation, cells attached to the upper surface of the filter were completely removed with a cotton swab. The filters were fixed in $70 \%$ methanol and stained with Giemsa solution. Cells that had migrated to the lower surface of the filter were counted manually in three random x100 fields, and the mean count was calculated. Each assay was performed three times in triplicate.

Proliferation assay. The proliferation potential of the NP-1inhibited WiDR cells was determined using a Cell Proliferation Biotrak ELISA kit (Amersham Biosciences UK Ltd.) according to the manufacturer's instructions. After siRNA removal, $1.5 \times 10^{4}$ WiDR cells were seeded on 96-well plates in complete medium in a humidified atmosphere at $37^{\circ} \mathrm{C}$ such that they would reach $60 \%$ confluence by the following day. After $24 \mathrm{~h}$, the medium was removed and 5-bromo-2'deoxyuridine (BrdU) solution (final concentration: $10 \mu \mathrm{M}$ $\mathrm{BrdU}$ ) was added to $1 \%$-FBS medium alone or to $1 \%$-FBS medium containing $20 \mathrm{ng} / \mathrm{ml}$ VEGF165. After $6 \mathrm{~h}$, the labeling medium was removed and subsequent steps were performed according to the Cell Proliferation Biotrak ELISA kit manufacturer's instructions. The resultant color was read at $450 \mathrm{~nm}$ using an ELISA reader (Corona Electronics Co., Katsuta, Japan). Each assay was performed three times in triplicate.

Apoptosis assay (FACS analysis). After treatment of WiDR cells as described for migration assays, each adherent treatment group in 6-well plates was treated with trypsin for $5 \mathrm{~min}$, suspended in complete medium, and pelleted by centrifugation at 1,000 rpm for $5 \mathrm{~min}$. Pelleted cells were resuspended in PBS, repelleted by centrifugation at $1,000 \mathrm{rpm}$ for $5 \mathrm{~min}$, and annexin V-fluorescein isothiocyanate (FITC)/propidium iodide (PI) staining was performed using an annexin V-FITC apoptosis detection kit (MBL, Nagoya, Japan) according to the manufacturer's recommended procedure. Cell samples were analyzed by flow cytometry using a FACSCalibur system (Becton-Dickinson, Franklin Lakes, NJ). Each assay was performed in triplicate.

Apoptosis assay [immunofluorescence staining for singlestranded DNA (ssDNA)]. After siRNA removal, 1.5x10 5 WiDR cells were seeded onto a two-chamber slide (Nalge Nunc International, Roskilde, Denmark) in complete medium in a humidified atmosphere at $37^{\circ} \mathrm{C}$ such that they would reach $60 \%$ confluence by the following day. After $24 \mathrm{~h}$, cells were fixed in $4 \%$ paraformaldehyde, washed in PBS containing $0.5 \%$ Triton $\mathrm{X}$, and incubated for $1 \mathrm{~h}$ with rabbit polyclonal ssDNA antibody A-4506 (1:200; Dako Corp., Carpinteria, CA). FITC-conjugated goat anti-rabbit IgG ALI4408 (Biosource, Camarillo, CA) was used as secondary antibody, and the slides were mounted in Vectashield Mounting Medium H1000 (Vector Laboratories Inc., Burlingame, CA). 
As reported by Tsukahara et al (32), we confirmed variation in the localization and intensity of ssDNA immunoreactivity within nuclei (Fig. 2D). In some cells, strong ssDNAimmunoreactive specks were observed in the vicinity of the nuclear membranes or within nuclei. In other cells, strong and homogeneous ssDNA immunoreactivity was observed throughout the nuclei. In the present study, both types were counted as apoptotic cells. For quantification of ssDNA staining, cells were counted manually in six random $\mathrm{x} 400$ fields, and the mean percentage of fluorescence-positive cells was calculated. The mean percentage was defined as the ssDNA labeling index. Each assay was performed three times in triplicate.

Immunohistochemical staining (IHC). IHC for NP-1, Ki-67, ssDNA, and CD34 was performed on formalin-fixed, paraffinembedded tissues cut into serial $4 \mu$ m-thick sections using an LSAB2 kit (Dako Corp.). NP-1, Ki-67, ssDNA, and CD34 were detected with mouse monoclonal anti-NP-1 antibody A-12 (1:100; Santa Cruz Biotechnology Inc.), mouse monoclonal anti-Ki-67 antibody M-7240 (1:50; Dako Corp.), rabbit polyclonal anti-ssDNA antibody A-4506 (1:200; Dako Corp.), and mouse monoclonal anti-CD34 antibody NU-4A1 (1:2; Nichirei, Tokyo, Japan). After deparaffinization and rehydration, tissue sections were pretreated for antigen retrieval by microwaving three times for $5 \mathrm{~min}$ each in $10 \mathrm{mM}$ citrate buffer (10 mM citrate monohydrate in distilled water, $\mathrm{pH} 6.0$ ) for NP-1 or in target retrieval solution (Dako Corp.) for Ki-67. For CD34, deparaffinized and rehydrated sections were pretreated with pronase (Trypsin 1:250, Difco Laboratories, Detroit, MI) for $30 \mathrm{~min}$ at $37^{\circ} \mathrm{C}$. For ssDNA, tissue sections were not treated for antigen retrieval. Subsequent steps were performed according to the manufacturer's instructions.

All negative controls were prepared as described above in the absence of primary antibody. Specific immunoreactive signals were not observed in any of the control sections (data not shown).

To quantify NP-1 immunolabeling, all slides were compared to internal controls, and the staining intensity of each colorectal carcinoma tissue was graded on a scale of $0-3$, with 0 representing no detectable staining (Fig. 4B), 1 representing faint staining, equivalent to that of apical or lateral colonic epithelial cells or mononuclear cells in adjacent normal tissue (20) (Fig. 4A), 2 representing moderate staining, and 3 representing strong staining (Fig. 4C). This score was defined as the staining intensity scale (SIS). Subsequently, the percentage of tumor cells with NP-1 staining was assessed by light microscopy. The mean value of the percentages obtained from each of the six fields examined per case was graded on a scale of $0-3$, with 0 representing $0-10 \%, 1$ representing 10-30\%, 2 representing 30-60\%, and 3 representing $60-100 \%$. This score was defined as the mean value score (MVS). Because the mean value of SIS plus MVS was 3.64, immunohistochemical staining for NP-1 was defined as a high level of NP-1 staining if SIS plus MVS was greater than the mean value.

As mentioned above, there was variation in the localization and intensity of ssDNA immunoreactivity within nuclei (Fig. 4F). In the present study, both specked and homogeneous staining were counted as representing apoptotic cells
(Fig. 4F). For ssDNA staining, cells were counted manually in six random $x 400$ fields and the mean per mill of stained cells was calculated. For Ki-67 staining (Fig. 4E), cells were counted manually in six random $\mathrm{x} 400$ fields and the mean percentage of stained cells was calculated. The mean percentage for Ki-67- and the mean per mill for ssDNA-stained cells was defined as the proliferation index and the apoptotic index, respectively. Two investigators who had no knowledge of the NP-1 staining status of the tumors counted the Ki-67- and ssDNA-stained cells.

For CD34 staining, microvessel density (MVD) was assessed by light microscopy at sites of the greatest numbers of capillaries and venules. CD34 staining was detected in the cytoplasm of vascular endothelial cells (Fig. 4D). As described by Weidner et al (33), the presence of vessel lumina was not necessary for a structure to be defined as a vessel. Microvessels appeared as brown capillaries or small clusters that stand out sharply from other tissue (Fig. 4D). Tumor sections were scanned at low power (x40 and x100) to identify highly vascular areas. After six areas with the highest neovascularization were identified, a vessel count was performed manually on x400 fields, and the mean of counts for six fields was calculated and defined as the mean MVD. Two investigators who had no knowledge of the NP-1 staining status of the tumors counted microvessels.

Statistical analysis. Statistical significance was evaluated by $\chi^{2}$ and t-test and differences between groups were judged to be significant at $\mathrm{P}<0.05$. In vivo data were expressed as mean \pm standard error of the mean (SEM) and in vitro data were expressed as mean \pm standard deviation (SD). Curves for overall survival were drawn according to the Kaplan-Meier method, and differences between the curves were analyzed by applying a log-rank test. The significance level was set at $5 \%$ for each analysis. All statistical analyses were performed with the SAS statistical package (SAS Institute Japan Ltd., Tokyo, Japan).

\section{Results}

VEGF isoforms, SEMA3A, and their receptors in colon carcinoma cell lines. The expression of VEGF isoforms and their receptors were determined in four colon carcinoma cell lines by semi-quantitative RT-PCR (Fig. 1A). HMVECs were used as a positive control. WiDR cells expressed VEGF isoforms and their receptor, NP-1, but not VEGFR-1, VEGFR-2 or NP-2. The other carcinoma cell lines tested variably expressed NP-1, NP-2, and VEGFR-1, but not VEGFR-2. All of the cell lines expressed SEMA3A and its receptor plexinA1. To exclude the influence of VEGF165 receptors other than NP-1, WiDR cells were used in subsequent experiments. NP-1 expression in WiDR cells was inhibited with RNAi technique. COLO320DM cells, which did not express NP-1, also used as a negative control for NP-1.

Inhibition of NP-1 expression by transfection of NP-1 siRNA into WiDR cells. First, we determined the concentrationdependent influence of transfected NP-1 siRNA. Total RNA was collected $48 \mathrm{~h}$ after transfection and analyzed by quantitative RT-PCR. Transfection of NP-1 siRNA and 
A
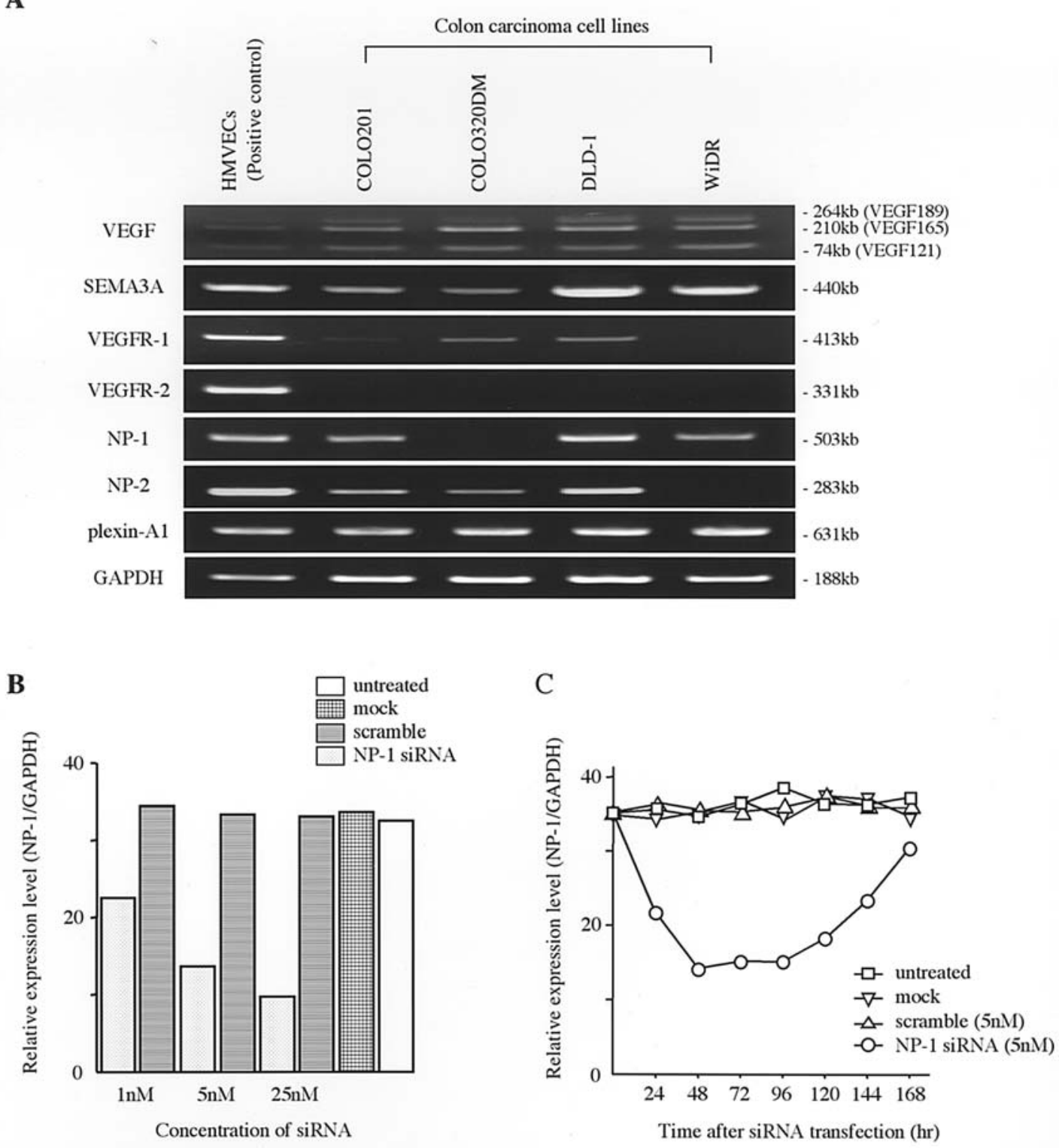

D

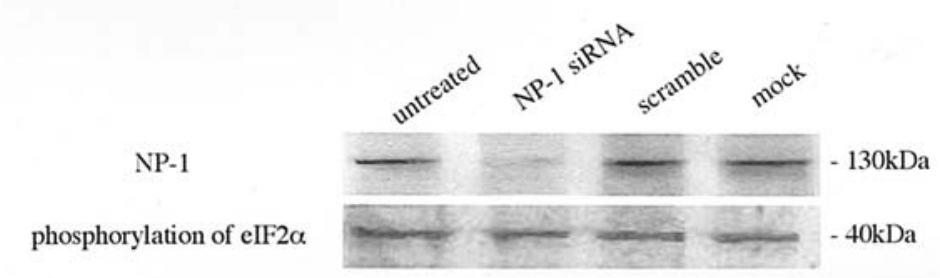

Figure 1. (A) The mRNA expression of VEGF isoforms, SEMA3A, and their receptors in four human colon adenocarcinoma cell lines as determined by semiquantitative RT-PCR. HMVECs were used as a positive control. (B) Concentration-dependent effect of transfection with NP-1 siRNA into WiDR cells on NP-1 mRNA expression level. mRNA expression levels were determined $48 \mathrm{~h}$ after transfection at various concentrations by quantitative RT-PCR. As negative controls, mRNA expression levels in response to transfection with scrambled siRNA targeting NP-1 (scramble), mock transfection (mock), and no treatment (untreated) were determined. (C) Effect of transfection with NP-1 siRNA into WiDR cells on NP-1 mRNA expression level over time. mRNA expression levels were determined at the indicated times after siRNA transfection by quantitative RT-PCR. (D) Protein expression levels of NP-1 and phosphorylation of the PKR substrate eIF $2 \alpha$ in response to transfection with NP-1 siRNA into WiDR cells. Protein expression levels were determined $48 \mathrm{~h}$ after transfection (final siRNA concentration: $5 \mathrm{nM}$ ) by Western blot analysis.

scrambled siRNA did not affect the level of GAPDH (data not shown). NP-1 mRNA expression at each concentration was standardized to GAPDH mRNA expression, which was assigned a value of one, and data were reported relative to
GAPDH mRNA expression. Transfection of siRNA designed to target NP-1 resulted in a concentration-dependent decrease in mRNA expression levels of NP-1 in WiDR cells (Fig. 1B). Next, the effect of transfection of NP-1 siRNA (final siRNA 
A
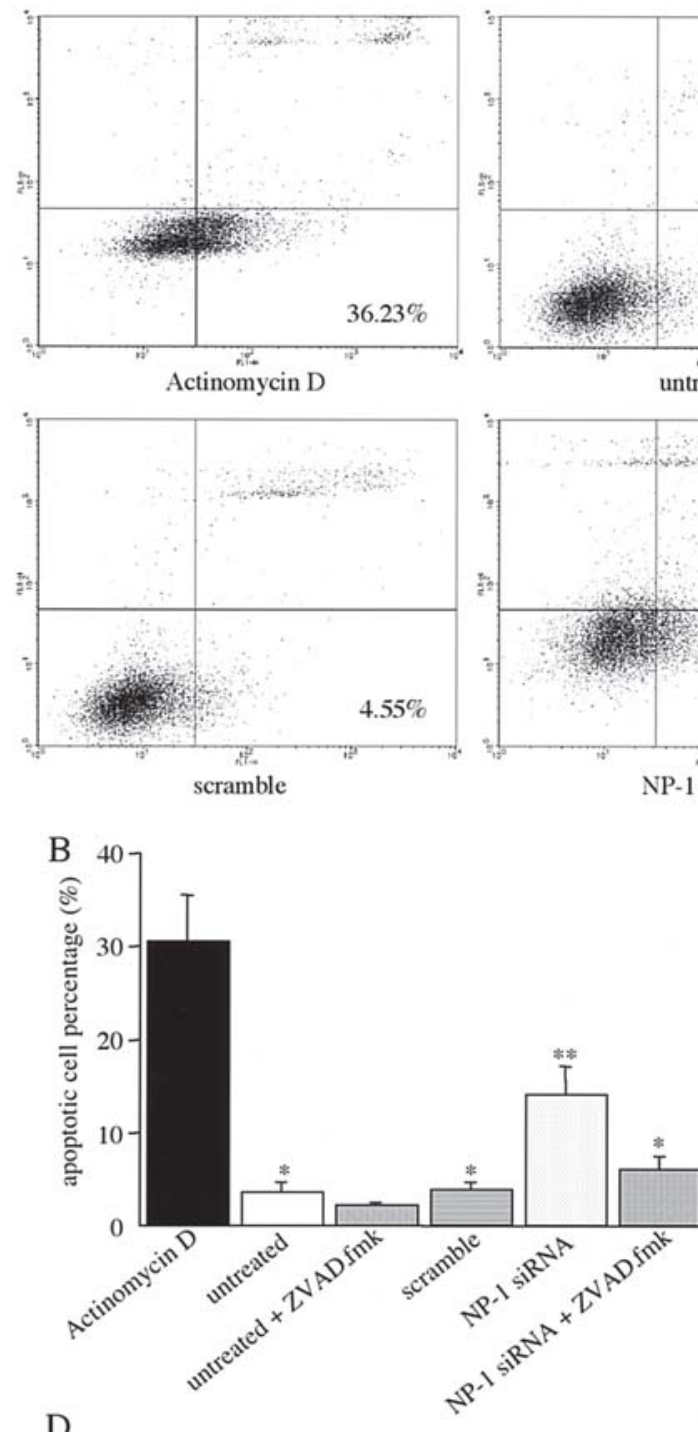

$\mathrm{D}$

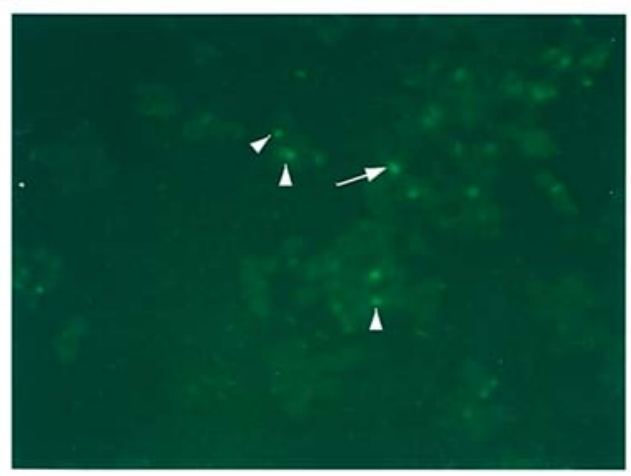

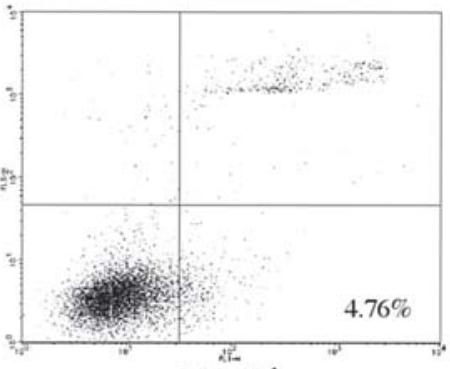

untreated

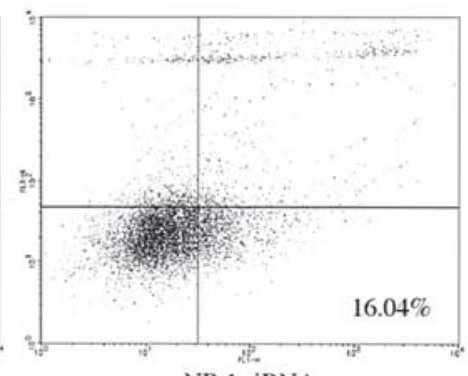

NP-1 siRNA

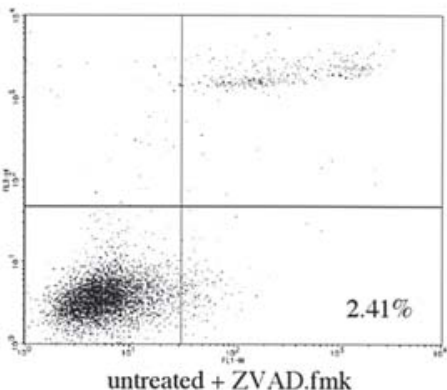

untreated + ZVAD.fmk

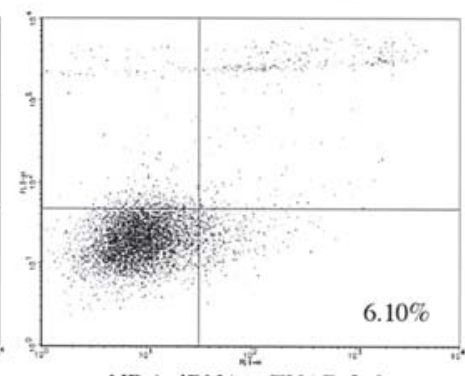

NP-1 siRNA + ZVAD.fmk
C

E

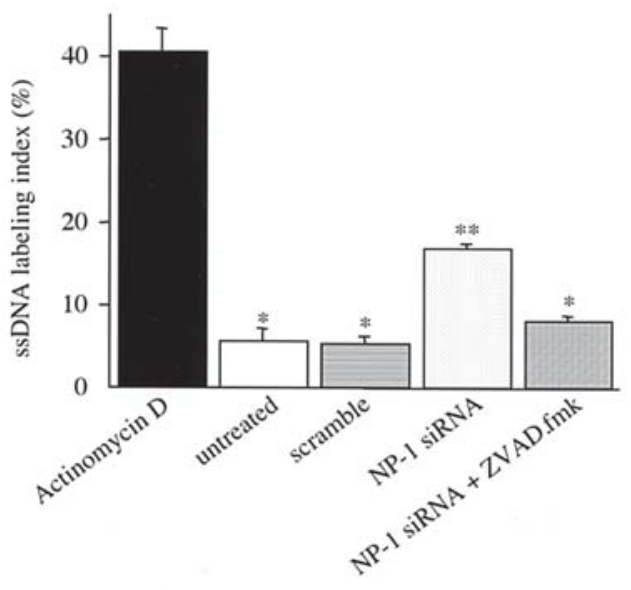

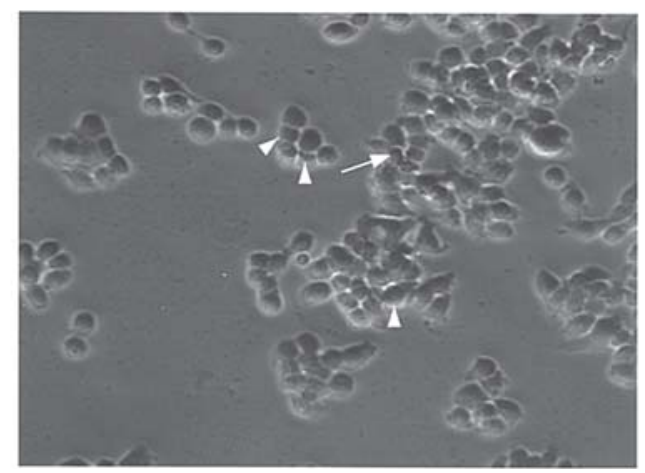

Figure 2. Apoptosis assay of human colon adenocarcinoma WiDR cells. (A) Representative dot plots of annexin V-FITC/PI two-parameter flow cytometry of each experiment. The lower-right quadrant shows apoptotic cells, which exclude PI (FL3-H) and bind FITC-annexin V (FL1-H) to phosphatidylserine exposed at the cell surface. Analysis showed that $4.76 \%$ of untreated WiDR cells and $4.55 \%$ of WiDR cells transfected with scrambled siRNA were apoptotic. Inhibition of NP-1 expression by transfection of NP-1 siRNA increased apoptosis (16.04\%). (B) Transfection of scrambled siRNA did not significantly affect apoptosis (scramble vs. untreated: $3.80 \pm 0.97 \%$ vs. $3.52 \pm 1.20 \%$ ). Inhibition of NP-1 expression by transfection of NP-1 siRNA significantly increased apoptosis compared to no treatment or transfection with scrambled siRNA (NP-1 siRNA vs. scramble: $14.22 \pm 9.44 \%$ vs. 3.80 $\pm 0.97 \%$; P=0.005). Addition of ZVAD.fmk to untreated cells did not significantly alter apoptosis (ZVAD.fmk vs. untreated: $2.30 \pm 0.23 \%$ vs. $3.52 \pm 1.20 \%$ ), but addition of ZVAD.fmk to NP-1 siRNA-transfected cells inhibited apoptosis significantly (NP-1 siRNA + ZVAD.fmk vs. NP-1 siRNA: $6.25 \pm 1.78 \%$ vs. 14.22 $\pm 9.44 \%$; P=0.0146). As a positive control, the addition of actinomycin D (final concentration: $10 \mathrm{mg} / \mathrm{ml}$ ) to untreated cells led to apoptosis $(30.55 \pm 4.92 \%)$. * No significant difference between no treatment, scrambled siRNA, and ZVAD.fmk treatment of cells transfected with NP-1 siRNA. ${ }^{* *} \mathrm{P}<0.05$ compared to no treatment, scrambled siRNA, and ZVAD.fmk treatment of cells transfected with NP-1 siRNA. (C) Apoptosis assay (immunofluorescence staining of ssDNA) of WiDR cells. Immunolabeling with an anti-ssDNA

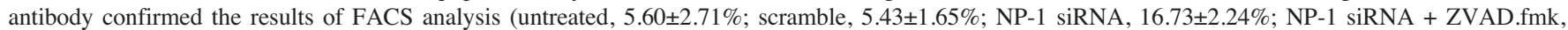
$8.20 \pm 0.917 \%$; actinomycin D, 40.67 $\pm 4.82 \%$ ). *No significant difference between no treatment, scrambled siRNA, and ZVAD.fmk treatment of cells transfected with NP-1 siRNA. ${ }^{* *} \mathrm{P}<0.05$ compared to no treatment, scrambled siRNA, and ZVAD.fmk treatment of cells transfected with NP-1 siRNA. (D) Representative immunofluorescence staining of ssDNA. (E) The same field by light microscopy of each experiment. Both speck-stained (arrowhead) and homogeneous (arrow) stained nuclei were counted as apoptotic cells. Original magnification:, x400 (A and B). Columns, mean; bars, standard deviation (SD). 
concentration: $5 \mathrm{nM}$ ) was examined over time by quantitative PCR to determine the effective duration of transfection of NP-1 siRNA for invasion, proliferation, and apoptosis assays. The mRNA level of NP-1 reached a minimal level at $48 \mathrm{~h}$ after transfection and gradually recovered to almost baseline level at $168 \mathrm{~h}$ (Fig. 1C). Suppression of the NP-1 protein level $48 \mathrm{~h}$ after transfection was confirmed by Western blotting (Fig. 1D). Recently, Sledz et al (34) reported that transfection of siRNA induced interferon (IFN)-mediated activation of the Jak-Stat pathway and global upregulation of IFN-stimulated genes in spite of the specificity of RNAi and that siRNA-mediated IFN induction was mediated by autophosphorylation of double-stranded RNA dependent protein kinase (PKR) and subsequent phosphorylation of eIF $2 \alpha$. To determine whether the PKR-dependent IFN pathway activated by siRNA transfection induced broad and complicating effects, we examined whether transfection of NP-1 siRNA affected the phosphorylation of eIF2 $\alpha$ (Fig. 1D). We confirmed that transfection of NP-1 siRNA into WiDR cells did not activate the PKR-dependent IFN pathway. Thereafter, we transfected $5 \mathrm{nM}$ siRNA and studied the effects from 48 to $144 \mathrm{~h}$ after transfection.

Effect of NP-1 siRNA transfection on apoptosis. We investigated whether WiDR cells transfected with NP-1 siRNA showed increased apoptosis. We analyzed dot plots of annexin V-FITC/PI two-parameter flow cytometry and immunolabeling for ssDNA. Representative dot plots are shown in Fig. 2A. Annexin V-FITC/PI apoptosis two-parameter flow cytometry showed that apoptosis was significantly increased by transfection with NP-1 siRNA $(14.22 \pm 9.44 \%)$ and not affected by transfection with scrambled siRNA $(3.80 \pm 0.97 \%$ ) (Fig. 2B). Addition of benzyloxycarbonyl-ValAla-Asp-(O-methyl)-fluoromethylketone (ZVAD.fmk) (Sigma Chemical Co., St. Louis, MO), a general caspase inhibitor, (final concentration: $100 \mu \mathrm{M}$ ) significantly inhibited this increased apoptosis $(6.25 \pm 1.78 \%)$ (Fig. 2B). Treatment of NP-1 siRNA transfected cells with ZVAD.fmk did not significantly alter the level of apoptosis compared to that induced by scrambled siRNA or untreated cells $(3.52 \pm 1.20 \%)$. Treatment of untreated cells with ZVAD.fmk $(2.30 \pm 0.23 \%)$ did not significantly alter the level of apoptosis compared to that induced by untreated cells. As a positive control, addition of actinomycin D (final concentration: $10 \mathrm{mg} / \mathrm{ml}$ ) (Sigma Chemical Co.) to untreated WiDR cells led to an apoptotic level of $30.55 \pm 4.92 \%$. We confirmed that transfection of NP-1 siRNA into COLO320DM, which did not express NP-1, did not alter the level of apoptosis compared to that induced by scrambled siRNA or untreated cells (data not shown). Immunolabeling with an anti-ssDNA antibody confirmed the results of FACS analysis (Fig. 2C). In subsequent proliferation and migration assays, transfection of NP-1 siRNA was performed in the presence of ZVAD.fmk to inhibit the influence of apoptosis by transfection of NP-1 siRNA.

Effect of NP-1 siRNA transfection on cell proliferation. We investigated whether transfection of NP-1 siRNA suppresses the proliferation of WiDR cells. The results showed that proliferation was not affected by transfection of NP-1 siRNA
A

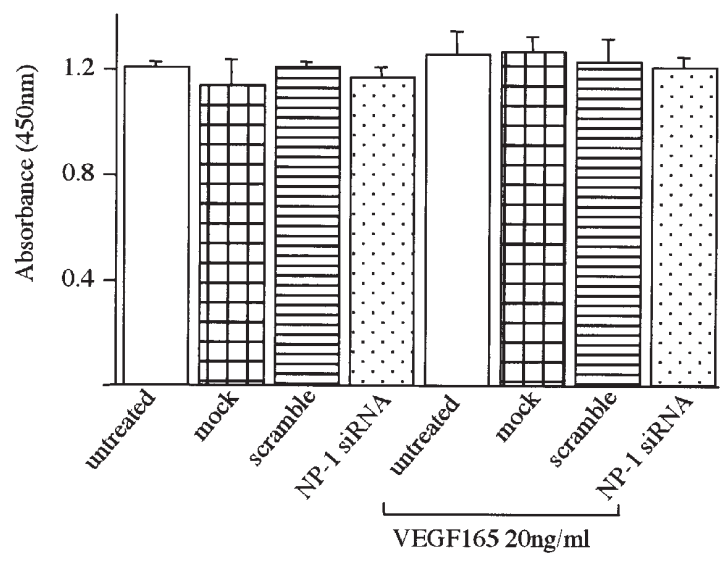

B

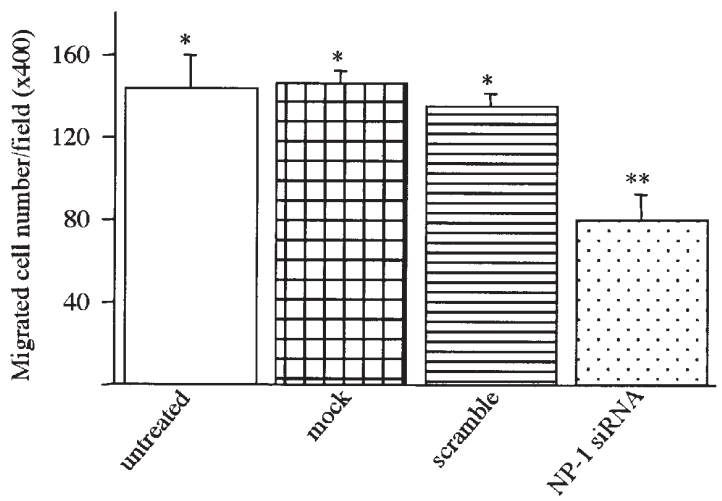

Figure 3. (A) Effect of inhibition of NP-1 expression by transfection of NP-1 siRNA on cell proliferation. No significant differences were observed, regardless of siRNA transfection or addition of VEGF165. (B) Effect of inhibition of NP-1 expression by transfection of NP-1 siRNA on cell migration. Transfection of NP-1 (79.6 \pm 12.4 cells/field) inhibited migration compared to no treatment $(143.3 \pm 17.1$ cells/field $)$, mock $(146.8 \pm 5.4$ cells/field $)$, or scrambled siRNA (134.6 \pm 7.3 cells/field). *No significant difference between no treatment, mock, and scrambled siRNA. ${ }^{* *} \mathrm{P}<0.05$ compared to no treatment, mock, and scrambled siRNA. Columns, mean; bars, SD.

(Fig. 3A). Addition of exogenous VEGF165 also did not alter the proliferation of WiDR cells (with or without siRNA transfection) (Fig. 3A).

Effect of NP-1 siRNA transfection on cell migration. Migration of WiDR cells was examined in response to NP-1 siRNA transfection by migration assay. Migration ability was significantly inhibited by transfection with NP-1 siRNA $(79.6 \pm 12.4$ cells/ field), compared to that in mock transfected cells $(146.8 \pm 5.4$ cells/field), transfection with scrambled siRNA (134.6 \pm 7.3 cells/field), and untreated cells $(143.3 \pm 17.1$ cells/field $)$ (Fig. 3B). Migration of COLO320DM was not altered by transfection of NP-1 siRNA (data not shown).

Clinicopathologic findings in relation to NP-1 immunolabeling in advanced colorectal carcinoma. Immunoreactivity for NP-1 was detected in the cytoplasm of carcinoma cells as well as endothelial cells, mononuclear cells, and apical or lateral colonic epithelial cells in adjacent normal tissue 

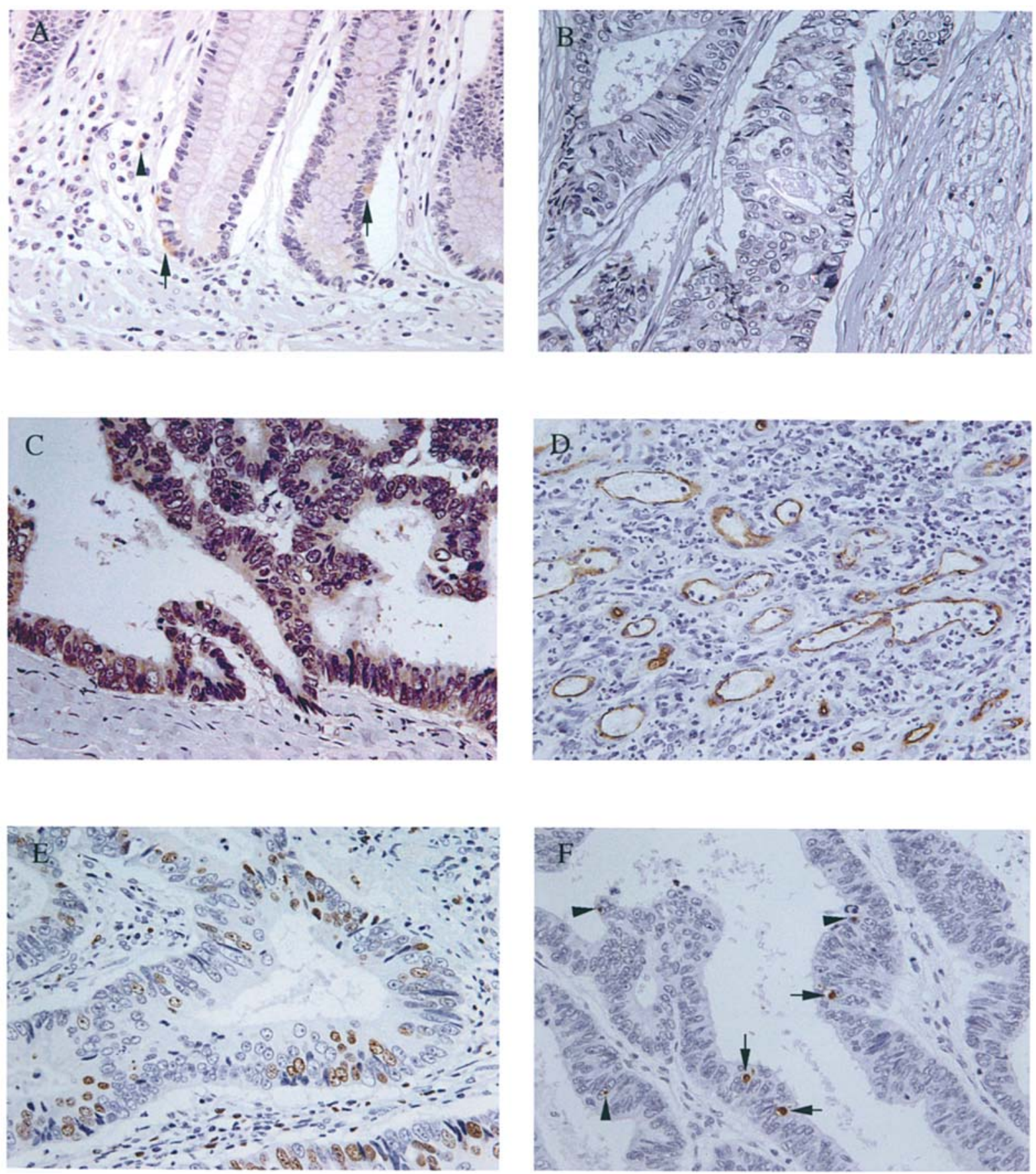

Figure 4. Representative human advanced colorectal carcinoma tissue sections subjected to NP-1, CD34, Ki-67, or ssDNA IHC. (A) NP-1 staining in adjacent normal tissue. Adjacent normal tissue did not show detectable NP-1 staining, with the exception of the lateral or apical portions of colonic epithelial cells (arrow) and mononuclear cells (arrowhead). (B) No NP-1 staining was detected in cancer cells. The staining intensity in cancer cells was fainter than that in apical colonic epithelial cells and mononuclear cells in adjacent normal tissue. (C) Positive NP-1 staining of cancer cells. NP-1 staining was detected in the cytoplasm of carcinoma cells. The staining intensity of cancer cells was stronger than that of apical colonic epithelial cells and mononuclear cells in adjacent normal tissue. (D) CD34 staining of cancer cells. CD34 staining was detected in the cytoplasm of vascular endothelial cells. (E) Ki-67 staining of cancer cells. Most of the Ki-67 immunoreactivity was localized within the nuclei of cancer cells or stromal cells. (F) ssDNA staining of cancer cells. Both speck-stained (arrowhead) and homogeneous stained cells (arrow) were counted as apoptotic cells. Original magnification, x400 (A-F).

(Fig. 4A and C). We focused on only NP-1 staining of tumor cells to estimate the biological malignant potential of NP-1 expression in tumor cells. Analysis of NP-1 staining in ECs and normal tissue was excluded from this study. Ninety-five of $146(65.1 \%)$ colorectal carcinomas showed high levels of NP-1 staining above the mean value (3.64) of SIS plus MVS (Table II). High levels of NP-1 staining correlated significantly with tumor stage (Dukes A, 47.6\%; Dukes B, 58.7\%; Dukes C,
64.4\%; Dukes D, 85.3\%), lymph node metastasis (73.0\%), and liver metastasis $(86.2 \%)$ (Table II). There was no correlation between high levels of NP-1 staining and site of lesion, tumor size, depth of invasion, histologic grade, lymphatic involvement, or venous involvement (Table II).

MVD and proliferation index were evaluated by IHC for CD34 and Ki-67, respectively. MVD and proliferation index were significantly greater in tumors with high levels of 
Table II. Clinicopathologic findings in relation to NP-1 immunolabeling in advanced colorectal carcinoma.

\begin{tabular}{|c|c|c|c|}
\hline $\begin{array}{l}\text { Clinicopathologic } \\
\text { findings }\end{array}$ & $\begin{array}{l}\text { No. of } \\
\text { cases }\end{array}$ & $\begin{array}{c}\text { High level of } \\
\text { NP-1 staining }(\%)\end{array}$ & P-value \\
\hline \multicolumn{4}{|l|}{ Site of lesion } \\
\hline Left colon & 111 & 61.3 & \multirow{2}{*}{0.086} \\
\hline Right colon & 35 & 77.1 & \\
\hline \multicolumn{4}{|l|}{ Tumor size (mm) } \\
\hline$<50$ & 83 & 62.7 & \multirow{2}{*}{0.482} \\
\hline$>50$ & 63 & 68.3 & \\
\hline \multicolumn{4}{|l|}{ Histological grade } \\
\hline Well & 45 & 63.6 & \multirow{3}{*}{0.940} \\
\hline Moderately & 84 & 66.7 & \\
\hline Poorly, mucinous & 17 & 64.7 & \\
\hline \multicolumn{4}{|l|}{ Depth of invasion } \\
\hline $\mathrm{mp}-\mathrm{ss}(\mathrm{al})$ & 99 & 62.6 & \multirow[t]{2}{*}{0.369} \\
\hline se (a2) - si (ai) & 47 & 70.2 & \\
\hline \multicolumn{4}{|c|}{ Lymphatic involvement } \\
\hline (+) & 123 & 68.3 & \multirow[t]{2}{*}{0.059} \\
\hline$(-)$ & 23 & 47.8 & \\
\hline \multicolumn{4}{|l|}{ Venous involvement } \\
\hline$(-)$ & 55 & 60.0 & 0.318 \\
\hline \multicolumn{4}{|c|}{ Lymph node metastasis } \\
\hline$(+)$ & 74 & 73.0 & \multirow{2}{*}{0.042} \\
\hline$(-)$ & 72 & 56.9 & \\
\hline \multicolumn{4}{|l|}{ Liver metastasis } \\
\hline$(+)$ & 29 & 86.2 & \multirow[t]{2}{*}{$<0.01$} \\
\hline$(-)$ & 117 & 59.8 & \\
\hline \multicolumn{4}{|l|}{ Dukes stage } \\
\hline A & 21 & 47.6 & \multirow{4}{*}{0.021} \\
\hline B & 46 & 58.7 & \\
\hline $\mathrm{C}$ & 45 & 64.4 & \\
\hline $\mathrm{D}$ & 34 & 85.3 & \\
\hline
\end{tabular}

NP-1 staining than in tumors with low levels of NP-1 staining $(60.4 \pm 2.2$ vessels/field vs. $47.8 \pm 2.4$ vessels/field, and $48.6 \pm 1.9 \%$ vs. $42.0 \pm 2.7 \%$, respectively) (Fig. 5A and B).
We also investigated apoptosis of advanced colorectal carcinoma by ssDNA immunoreactivity. The apoptotic index was significantly less in tumors with high levels of NP-1 staining $(5.70 \pm 0.54 \%$ ) than in tumors with low levels of NP-1 staining (8.44 $\pm 1.01 \%$ ) (Fig. 5C).

Relationship between NP-1 immunolabeling and postoperative survival. To investigate whether high levels of NP-1 staining were associated with prognosis of patients with colorectal carcinoma, we selected 103 patients who had undergone curative surgery and were followed-up at our hospital. The mean follow-up time of the 75 surviving patients was 71.6 months (range, 2-154 months). The remaining 28 patients died between 0 and 81 months (mean, 33.9 months). KaplanMeier analysis showed that the survival rate of patients with tumors with high levels of NP-1 staining was significantly less than that of patients with tumors with low levels of NP-1 staining (Fig. 5D). A multivariate analysis with logistic regression for 5-year survival in patients with curative surgery confirmed that a high level of NP-1 staining was a significant factor to predict a poor prognosis (Table III).

\section{Discussion}

NP-1 appears to function as a coreceptor for VEGFR-2 (7) and for plexins $(8,9)$ because it possesses a short intracellular domain, not including the tyrosine kinase domain. However, it has been reported that NP-1 alone can mediate VEGFinduced EC migration (12) and that NP-1 can play an essential role in autocrine antiapoptotic signaling by VEGF in NP-1-positive breast carcinoma cells lacking VEGFR-2 $(21,22)$. A balance between VEGF165 and SEMA (SEMA3A, $3 \mathrm{~B})$ expression results in promotion or repression of cell survival and migration mediated by NP-1 in porcine aortic ECs, neural progenitor cells, and ovarian, breast, and lung carcinoma cells lacking VEGFR-1 and/or -2 (24,26-28,35,36). Namely, predominant VEGF165 represses apoptosis and promotes cell survival and migration mediated by NP-1 even in the presence of SEMA $(24,26-28,35,36)$. Because WiDR cells constitutively express NP-1 and plexin-A1 as well as its ligand, SEMA3A, it is possible that the complex of NP-1, plexin-A1 and SEMA3A may promote apoptosis. However, considering that apoptosis of WiDR cells is not significantly

Table III. Multivariate analysis with logistic regression for 5-year survival rate in patients treated with curative surgery.

\begin{tabular}{lccc}
\hline Risk factor & Odds ratio (95\% confidence interval) & P-value & Referent factor \\
\hline Sex (male) & $1.016(0.305-3.380)$ & 0.9791 & Sex (female) \\
Depth of invasion [se (a2) - si (ai)] & $2.689(0.729-9.226)$ & 0.0751 & Depth of invasion [mp - ss (al)] \\
Histological grade & $2.264(0.641-7.996)$ & 0.2041 & Histological grade (well) \\
$\quad$ Moderate, poor, mucinous) & $1.201(0.332-4.335)$ & & Venous involvement (-) \\
Venous involvement (+) & $2.046(0.200-20.960)$ & 0.7802 & Lymphatic involvement (-) \\
Lymphatic involvement (+) & $5.451(1.423-20.880)$ & 0.0133 & Low level of NP-1 staining \\
High level of NP-1 staining & $11.545(3.216-41.443)$ & 0.0028 & Lymph node metastasis (-) \\
Lymph node metastasis (+) & & &
\end{tabular}


A

MVD (vessels/field)

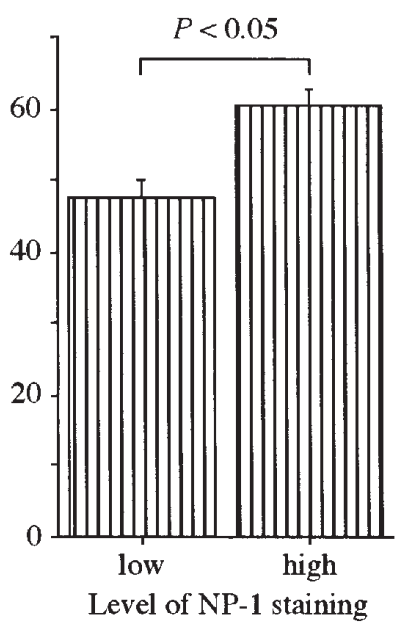

B

Proliferation index $(\%)$

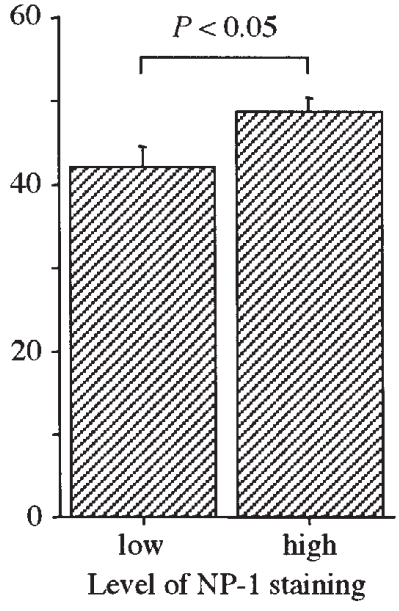

C

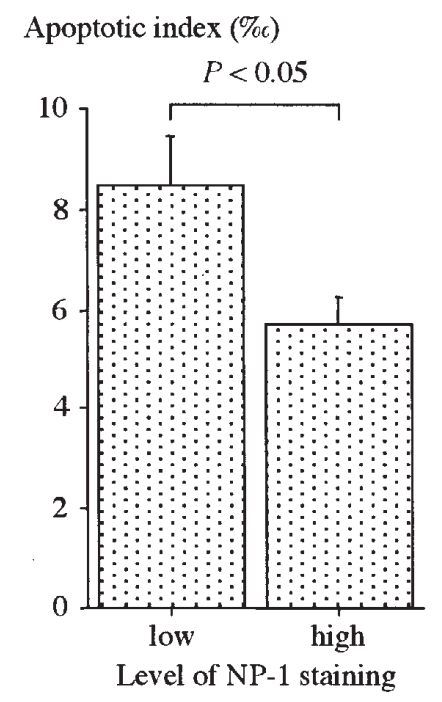

$\mathrm{D}$

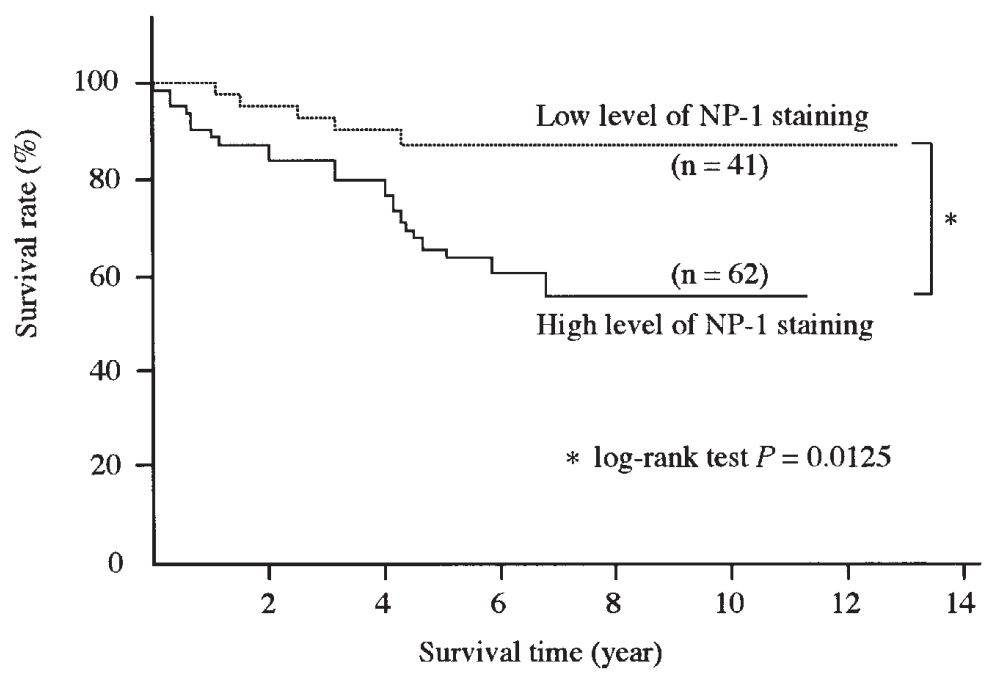

Figure 5. Relationship between NP-1 staining and MVD (A), proliferation index (B), and apoptotic index (C), in human advanced colorectal carcinoma tissue. MVD and proliferation index were significantly greater in tumors with high levels of NP-1 staining than in tumors with low levels of NP-1 staining $(60.4 \pm 2.2$ vessels/field vs. $47.8 \pm 2.4$ vessels/field; $\mathrm{P}<0.01,48.6 \pm 1.9 \%$ vs. $42.0 \pm 2.7 \%$; $\mathrm{P}<0.05$, respectively). Apoptotic index was significantly lower in tumors with high levels of NP-1 staining than in tumors with low levels of NP-1 staining $(5.70 \pm 0.54 \%$ vs. $8.44 \pm 1.01 \%$; P $<0.05)$. Columns, mean; bars, standard error of the mean (SEM). (D) Overall survival of 103 patients with advanced human colorectal carcinoma who underwent curative surgery relative to NP-1 staining of tumor tissue. There was a significant difference in survival time between those showing high levels of NP-1 staining and those showing low levels of NP-1 staining.

inhibited by addition of ZVAD.fmk, a general caspase inhibitor, and that apoptosis is promoted by specific inhibition of NP-1 protein expression by RNAi technique, apoptosis of WiDR cells is inhibited by predominant VEGF165 even in the presence of SEMA3A and plexin-A1, and NP-1 expressed by WiDR cells also appears to be related to inhibition of apoptosis under the predominant influence of VEGF165. Considering that the apoptosis of WiDR cells transfected with NP-1 siRNA is significantly inhibited by addition of ZVAD.fmk, apoptosis induced by NP-1 inhibition appears to be dependent on caspases (37). However, the signal transduction pathway of apoptosis associated with NP-1 is not characterized. Additional studies will be necessary to elucidate the mechanism by which this apoptosis occurs.
We and others (25) have suggested that the binding of VEGF165 to NP-1 on tumor cells directly mediates tumor cell migration. As expected, WiDR cell migration was inhibited by inhibition of endogenous NP-1 protein expression by transfection of NP-1 siRNA. Parikh et al reported that transfection of NP-1 expression vector into colon cancer cells leads to increased tumor cell migration in response to VEGF (25). However, Bachelder et al (24) recently reported that human breast cancer cell migration is promoted by inhibition of NP-1 expression by transfection of NP-1 siRNA. As noted by Bachelder et al (24), this inconsistency may be due to differences in the ratio of endogenous VEGF165 and SEMA3A expression in carcinoma cell lines. That is, WiDR cells showed promotion of cell migration and inhibition of cell apoptosis 
in response to the predominant influence of VEGF165, even in the presence of SEMA3A and plexin-A1. The breast cancer cell line used by Bachelder et al showed inhibition of cell migration in response to the predominant influence of SEMA3A.

In human tissue samples, we observed that NP-1 was expressed in the cytoplasm not only of carcinoma cells but also of endothelial cells, mononuclear cells, and the apical or lateral colonic epithelial cells. Thus, it would be inappropriate to evaluate the levels of NP-1 expression in samples of total RNA or total protein from resected colorectal carcinoma tissues, which include ECs, mononuclear cells and apical colonic epithelium, to estimate the malignant potential of NP-1 expression in colorectal carcinoma. We analyzed NP-1 expression in colorectal carcinoma by IHC to avoid this issue. IHC showed that high levels of NP-1 staining by tumor cells were significantly associated with liver and lymph node metastasis and with tumor stage. These findings in patients with colon carcinoma were consistent with the results of a previous report (20) indicating that NP-1 contributes to tumor metastasis.

It has been shown that VEGF binding to both NP-1 and VEGFR-2 on ECs leads to increased migration and chemotactic activity (7). Parikh et al recently showed that conditioned medium from NP-1-transfected cells leads to increased EC migration in a two-chamber assay and that transfection of NP-1 into human colon adenocarcinoma cells leads to increased angiogenesis in nude mice (25). In our in vitro study, inhibition of endogenous NP-1 expression by RNAi technique reveals that there are autocrine pathways for apoptosis and migration. Thus, we assessed the role of NP-1 in proliferation (proliferation index), apoptosis (apoptotic index), and angiogenesis (MVD) in human tissues. IHC showed that increased levels of NP-1 staining were significantly associated with increased proliferation and angiogenesis and with decreased apoptosis. In our in vitro study, cell proliferation was not influenced by inhibition of NP-1 expression. However, the proliferation index was significantly greater in tissues showing high levels of NP-1 staining in our in vivo study. The precise mechanism for this inconsistency is unknown. But, we and others $(13,25)$ have speculated that VEGF trapped by NP-1 on tumor cells may also bind to VEGFR-2 on ECs adjacent to the tumor and that angiogenesis and tumor growth may be induced as a result of juxtacrine mechanism for NP-1.

Prognosis and choice of therapy for most colorectal carcinoma patients are based on histologic type and tumor stage. We observed patients via follow-up examinations to determine whether NP-1 expression is predictive of which patients are likely to have recurrences. As expected, prognosis significantly correlated with level of NP-1 staining in colorectal tissues. Although this finding is partially consistent with those of a previous report in non-small cell lung carcinoma (17), this is, to our knowledge, the first study to investigate the relationship between increased levels of NP-1 staining and prognosis in human colorectal carcinoma tissues. Analysis of NP-1 in surgical tissues may provide clinicians with useful information with respect to identification of patients in need of adjuvant chemotherapy.

In conclusion, our study shows that there are autocrine survival and migration pathways mediated by the interaction of NP-1 and its ligands, VEGF165 and SEMA, in a colon carcinoma cell line. High levels of NP-1 staining in human colorectal carcinoma tissues result in increased tumor proliferation and angiogenesis and in decreased apoptosis. Therefore, high levels of NP-1 staining correlate with liver and/or lymph node metastasis and with prognosis in patients with advanced colorectal carcinoma and may be a useful prognostic indicator in patients with advanced colorectal carcinoma. Consideration of NP-1 expression may help identify patients in need of further treatment such as adjuvant chemotherapy or aggressive follow-up examination after surgical resection.

\section{Acknowledgements}

We thank Dr Masaru Shimamoto for assistance with FACS analysis and Ms. Kyoko Kunimitsu for her excellent technical assistance.

\section{References}

1. Fujisawa H, Takagi S and Hirata T: Growth-associated expression of a membrane protein, neuropilin, in Xenopus optic nerve fibers. Dev Neurosci 17: 343-349, 1995.

2. He Z and Tessier-Lavigne M: Neuropilin is a receptor for the axonal chemorepellent Semaphorin III. Cell 90: 739-751, 1997.

3. Kolodkin AL, Levengood DV, Rowe EG, Tai YT, Giger RJ and Ginty DD: Neuropilin is a semaphorin III receptor. Cell 90: 753-762, 1997.

4. Rossignol M, Gagnon ML and Klagsbrun M: Genomic organization of human neuropilin-1 and neuropilin-2 genes: identification and distribution of splice variants and soluble isoforms. Genomics 70: 211-222, 2000.

5. Kitsukawa T, Shimono A, Kawakami A, Kondoh $\mathrm{H}$ and Fujisawa H: Overexpression of a membrane protein, neuropilin, in chimeric mice causes anomalies in the cardiovascular system, nervous system and limbs. Development 121: 4309-4318, 1995.

6. Kawasaki T, Kitsukawa T, Bekku Y, et al: A requirement for neuropilin-1 in embryonic vessel formation. Development 126 : 4895-4902, 1999.

7. Soker S, Takashima S, Miao HQ, Neufeld G and Klagsbrun M: Neuropilin-1 is expressed by endothelial and tumor cells as an isoform-specific receptor for vascular endothelial growth factor. Cell 92: 735-745, 1998 .

8. Takahashi T, Fournier A, Nakamura F, et al: Plexin-neuropilin1 complexes form functional semaphorin-3A receptors. Cell 99: 59-69, 1999.

9. Tamagnone L, Artigiani S, Chen H, et al: Plexins are a large family of receptors for transmembrane, secreted, and GPIanchored semaphorins in vertebrates. Cell 99: 71-80, 1999.

10. Cai H and Reed RR: Cloning and characterization of neuropilin-1interacting protein: a PSD-95/Dlg/ZO-1 domain-containing protein that interacts with the cytoplasmic domain of neuropilin-1. J Neurosci 19: 6519-6527, 1999.

11. De Vries L, Lou X, Zhao G, Zheng B and Farquhar MG: GIPC, a PDZ domain containing protein, interacts specifically with the C terminus of RGS-GAIP. Proc Natl Acad Sci USA 95: 12340-12345, 1998 .

12. Wang L, Zeng H, Wang P, Soker S and Mukhopadhyay D: Neuropilin-1-mediated vascular permeability factor/vascular endothelial growth factor-dependent endothelial cell migration. J Biol Chem 278: 48848-48860, 2003.

13. Miao HQ, Lee P, Lin H, Soker S and Klagsbrun M: Neuropilin-1 expression by tumor cells promotes tumor angiogenesis and progression. FASEB J 14: 2532-2539, 2000.

14. Ding H, Wu X, Roncari L, et al: Expression and regulation of neuropilin-1 in human astrocytomas. Int J Cancer 88: 584-592, 2000.

15. Latil A, Bièche I, Pesche S, et al: VEGF overexpression in clinically localized prostate tumors and neuropilin-1 overexpression in metastatic forms. Int J Cancer 89: 167-171, 2000.

16. Fukhari M, Pullirsch D, Abraham D, et al: Selective upregulation of vascular endothelial growth factor receptors neuropilin-1 and -2 in human neuroblastoma. Cancer 94: 258-263, 2002 . 
17. Kawakami T, Tokunaga $\mathrm{T}$, Hatanaka $\mathrm{H}$, et al: Neuropilin 1 and neuropilin 2 co-expression is significantly correlated with increased vascularity and poor prognosis in nonsmall cell lung carcinoma. Cancer 95: 2196-2201, 2002.

18. Akagi M, Kawaguchi M, Liu W, et al: Induction of neuropilin-1 and vascular endothelial growth factor by epidermal growth factor in human gastric cancer cells. Br J Cancer 88: 796-802, 2003.

19. Parikh AA, Liu WB, Fan F, et al: Expression and regulation of the novel vascular endothelial growth factor receptor neuropilin1 by epidermal growth factor in human pancreatic carcinoma. Cancer 98: 720-729, 2003.

20. Hansel DE, Wilentz RE, Yeo CJ, Schulick RD, Montgomery E and Maitra A: Expression of neuropilin-1 in high-grade dysplasia, invasive cancer, and metastases of the human gastrointestinal tract. Am J Surg Pathol 28: 347-356, 2004.

21. Bachelder RE, Crago A, Chung J, et al: Vascular endothelial growth factor is an autocrine survival factor for neuropilinexpressing breast carcinoma cells. Cancer Res 61: 5736-5740, 2001.

22. Barr MP, Byrne AM, Duffy AM, et al: A peptide corresponding to the neuropilin-1-binding site on VEGF165 induces apoptosis of neuropilin-1-expressing breast tumour cells. Br J Cancer 92: 328-333, 2005.

23. Bachelder RE, Wendt MA and Mercurio AM: Vascular endothelial growth factor promotes breast carcinoma invasion in an autocrine manner by regulating the chemokine receptor CXCR4. Cancer Res 62: 7203-7206, 2002.

24. Bachelder RE, Lipscomb EA, Lin X, et al: Competing autocrine pathways involving alternative neuropilin-1 ligands regulate chemotaxis of carcinoma cells. Cancer Res 63: 5230-5233, 2003.

25. Parikh AA, Fan F, Liu WB, et al: Neuropilin-1 in human colon cancer expression, regulation, and role in induction of angiogenesis. Am J Pathol 164: 2139-2151, 2004.

26. Tomizawa Y, Sekido Y, Kondo M, et al: Inhibition of lung cancer cell growth and induction of apoptosis after reexpression of $3 \mathrm{p} 21.3$ candidate tumor suppressor gene SEMA3B. Proc Natl Acad Sci USA 98: 13954-13959, 2001.
27. Tse C, Xiang RH, Bracht $T$ and Naylor SL: Human semaphorin 3B (SEMA3B) located at chromosome 3p21.3 suppresses tumor formation in an adenocarcinoma cell line. Cancer Res 62: 542-546, 2002.

28. Castro-Rivera E, Ran S, Thorpe P and Minna JD: Semaphorin 3B (SEMA3B) induces apoptosis in lung and breast cancer, whereas VEGF165 antagonizes this effect. Proc Natl Acad Sci USA 101: 11432-11437, 2004.

29. Stanley RH and Lauri AA: World Health Organization classification of tumours, pathology and genetics of tumors of the digestive system. International Agency for Research on Cancer Press, Lyon, pp104-119, 2000.

30. Japanese Society for Cancer of the Colon and Rectum: General rules for clinical and pathological studies on cancer of the colon, rectum and anus. 6th edition. Kanehara Publising Co., Tokyo, 1998.

31. Kuora AN, Liu W, Kitadai Y, Singh RK, Radinsky R and Ellis LM: Regulation of vascular endothelial growth factor expression in human colon carcinoma cells by cell density. Cancer Res 56: 3891-3894, 1996.

32. Tsukahara S, Inami K, Maekawa F, et al: Postnatal apoptosis, development, and sex difference in the lateral septum of rats. J Comp Neurol 475: 177-187, 2004

33. Weidner N, Semple JP, Welch WR and Folkman J: Tumor angiogenesis and metastasis: correlation in invasive breast carcinoma. N Engl J Med 324: 1-8, 1991.

34. Sledz CA, Holko M, De Veer MJ, Silverman RH and Williams BR: Activation of the interferon system by shortinterfering RNAs. Nat Cell Biol 5: 834-839, 2003.

35. Miao HQ, Soker S, Feiner L, Alonso JL, Raper JA and Klagsbrun M: Neuropilin-1 mediates collapsin-1/semaphorin III inhibition of endothelial cell motility: functional competition of collapsin-1 and vascular endothelial growth factor-165. J Cell Biol 146: 233-241, 1999

36. Bagnard D, Vaillant C, Khuth ST, et al: Semaphorin 3Avascular endothelial growth factor-165 balance mediates migration and apoptosis of neural progenitor cells by the recruitment of shared receptor. J Neurosci 21: 3332-3341, 2001.

37. Green DR. Apoptotic pathways: the roads to ruin. Cell 94: 695-698, 1998. 